\title{
Incretin Responses to Oral Glucose Load in Japanese Non-Obese Healthy Subjects
}

Etsuko Nagai · Tomoyuki Katsuno · Jun-ichiro Miyagawa · Kosuke Konishi · Masayuki Miuchi · Fumihiro Ochi · Yoshiki Kusunoki · Masaru Tokuda Kazuki Murai · Tomoya Hamaguchi · Mitsuyoshi Namba

Received: November 9, 2010 / Published online: February 10, 2011

(C) The Author(s) 2011. This article is published with open access at Springerlink.com

\section{ABSTRACT}

Introduction: Recently, incretin-related therapy has been developed for the new treatment of diabetes mellitus; however, incretin response to glucose ingestion in normal glucose tolerant (NGT) subjects has not been clarified in detail with special reference to the role of incretin hormones, glucagon, and a family history of diabetes. Methods: We conducted a 75 g oral glucose tolerance test in 30 NGT subjects. Results: The total glucose-dependent insulinotropic peptide (GIP)-AUC ${ }_{0-120}$ (area under the curve over

Etsuko Nagai $(\bowtie) \cdot$ Tomoyuki Katsuno $\cdot$ Jun-ichiro Miyagawa · Kosuke Konishi · Masayuki Miuchi · Fumihiro Ochi · Yoshiki Kusunoki · Masaru Tokuda · Kazuki Murai $\cdot$ Mitsuyoshi Namba Division of Diabetes and Metabolism, Department of Internal Medicine, Hyogo College of Medicine, 1-1, Mukogawa-cho, Nishinomiya, Hyogo 663-8501, Japan. Email: e-nagai@hyo-med.ac.jp

Tomoya Hamaguchi

Division of Innovative Diabetes Treatment, Department of Internal Medicine, Hyogo College of Medicine, Hyogo, Japan a period of 0-120 minutes) was correlated with immunoreactive insulin (IRI)-AUC ${ }_{0-120}$ $(P<0.05)$, insulinogenic index (II; $P<0.05), \Delta$ IRI between 0 and 120 minutes $(P<0.05)$. Active glucagon-like peptide-1 (GLP-1) AUC $_{0-120}$ was correlated inversely both with $\Delta$ glucose between 0 and 30 minutes $(P<0.01)$ and with $\Delta$ immunoreactive glucagon between 0 and 30 minutes $(P<0.05) . \Delta$ Total GIP between 0 and 15 minutes $(P<0.01), \Delta$ total GIP between 0 and 30 minutes $(P<0.05)$, and the total GIP$\mathrm{AUC}_{0-120}(P<0.05)$ in the subjects with a family history of type 2 diabetes were significantly higher than those in the subjects without a family history. Conclusion: These results suggest that GIP possibly facilitates insulin secretion in response to oral glucose load directly and active GLP-1 may exert the glucoregulatory action via the suppression of glucagon secretion in NGT subjects. Notably, the subjects with a family history of diabetes exert significantly higher GIP response in the early phase of glucose load compared with those without a family history.

Keywords: diabetes mellitus; glucagon; glucagonlike peptide-1; glucose-dependent insulinotropic polypeptide; incretin; insulin 


\section{INTRODUCTION}

Glucose-dependent insulinotropic polypeptide (GIP) and glucagon-like peptide-1 (GLP-1) are incretin hormones that are released from enteroendocrine cells within minutes after food intake. GIP is secreted from enteroendocrine cells (K cells) primarily in the proximal small intestine (duodenum and jejunum), while GLP-1 is secreted from enteroendocrine cells (L cells) that are scattered throughout the small bowel (primarily in the distal portion) and colon. ${ }^{1}$ Both GIP and GLP-1 have been shown to stimulate insulin secretion in response to glucose and nutrient ingestion. ${ }^{2}$ The primary role of GIP is supposed to stimulate the secretion of insulin from pancreatic $\beta$ cells, especially in the postprandial state. In addition to its insulinotropic effect, GLP-1 has a potent glucagonostatic action, inhibits gastric emptying, decreases food intake, and slows the rate of endogenous glucose production, all of which would ameliorate the blood glucose levels in type 2 diabetes mellitus (T2DM). GLP-1 shows direct effects through GLP-1 receptors in the hypothalamus, thereby regulating the appetite, food intake, and body weight in the "gut-brain axis" (the reciprocal system between the gastrointestinal tract and central nervous system to regulate short- and long-term energy homeostasis). ${ }^{1}$

The earlier studies on the response of both incretin hormones to an oral glucose tolerance test (OGTT) and test meal revealed that the incretin effect of Caucasian patients with T2DM is significantly lower than healthy subjects. ${ }^{3,4}$ Conversely, in the three studies demonstrating incretin responses after ingestion of glucose and/ or nutrients in Japanese subjects, ${ }^{5-7}$ any difference between T2DM patients with or without obesity and nondiabetic control subjects could not be found out.
Whether the abnormality of the incretin response to the nutrient might be involved in the pathophysiological mechanisms of the development of T2DM or not awaits further investigation.

At the first step of the analysis of the mechanism, it is necessary to reveal the response of incretin to glucose or food intake in normal glucose-tolerant (NGT) subjects in detail with special reference to the relationship between incretin hormone responses and insulin, glucagon secretion, gender, metabolic parameters inclusive of body mass index (BMI), waist circumference, and a family history of diabetes in particular.

In this study, the various parameters were investigated after an intake of $75 \mathrm{~g}$ glucose in order to clarify the relationship between the responses of incretin hormones and glucose, insulin, or glucagon in 30 healthy subjects who are currently NGT.

\section{MATERIALS AND METHODS}

\section{Materials}

Thirty healthy subjects, who were a group of medical students within a pregraduate course, participated in this study. All of them had NGT. The exclusion criteria were subjects who had any major illness or premenopausal women who were pregnant or nursing. This study has been approved by the Ethics Committee of Hyogo College of Medicine. All participants provided written informed consent before the start of the study.

\section{Methods}

To identify the baseline characteristics of incretin secretion in Japanese subjects, the influence of body weight, BMI, height, gender, and a family 
history of diabetes on the hormonal response to oral glucose ingestion were also examined.

The OGTT consisted of ingesting $75 \mathrm{~g}$ glucose (Toleran $\mathrm{G}^{\circledR}$, Ajinomoto Pharma, Tokyo, Japan) in the overnight fasting state within 5 minutes. For active GLP-1 and total GIP analysis, catheters were placed in cubital veins and blood samples were withdrawn directly into the blood collection ethylenediaminetetraacetic acid-disodium salt coated tubes $(1.25 \mathrm{mg} / \mathrm{mL}$ blood) containing aprotinin and an inhibitor of dipeptidyl peptidase-4 $(10 \mu \mathrm{L} / \mathrm{mL}$ blood; Linco Research Inc., MO, USA) before the start of the OGTT and 15, 30, 60, and 120 minutes after ingestion, respectively. The levels of plasma glucose, immunoreactive insulin (IRI), immunoreactive glucagon (IRG), total GIP, and active GLP-1 were measured at each time interval. Plasma glucose concentrations were measured immediately by the glucose oxidase method. IRI was measured using chemiluminescent enzyme immunoassay (Fujirebio Inc., Tokyo, Japan). Plasma levels of glucagon were measured using a radioimmunoassay via the glucagon kit daiichi-II (TFB Corp., CA, USA). Plasma levels of active GLP-1 were measured using an enzymelinked immunosorbent assay (ELISA), using the GLP-1 active ELISA kit (Millipore Corp., MA, USA) according to the manufacturer's instructions. Plasma levels of the total GIP were also measured using an ELISA, using the human GIP (total) ELISA kit (Millipore Corp., MA, USA).

\section{Statistical Analysis}

The results of statistical analysis were shown as the mean \pm standard deviation (SD) unless otherwise specified. The trapezoidal method was used to calculate all areas under the curves (AUCs). The homeostasis model assessment was used both for assessing insulin resistance (HOMA-R) and insulin secretion (HOMA- $\beta$ ). ${ }^{8}$ HOMA-R was calculated as fasting plasma glucose $(\mathrm{mg} / \mathrm{dL}) \times$ fasting serum insulin $(\mu \mathrm{IU} / \mathrm{mL}) / 405$. HOMA- $\beta$ was calculated as $(360 \times$ fasting serum insulin $[\mu \mathrm{IU} / \mathrm{mL}]$ ) / (fasting plasma glucose $[\mathrm{mg} / \mathrm{dL}]$ -63). The insulinogenic index (II) was calculated as the ratio of the increment of serum insulin to plasma glucose concentration 30 minutes after an oral glucose load (IRI $\Delta_{0-30 \text { minutes }}$ glucose $\left.\Delta_{0-30 \text { minutes }}\right) .{ }^{9}$ Single Pearson correlation analysis was used to examine bivariate relationships. The unpaired $t$-test was used when two separate sets of samples (family history $[+] /[-]$ ) were obtained. A $P$ value of less than 0.05 was taken to indicate statistically significant difference.

\section{RESULTS}

As shown in Table 1, the age of subjects was $24.7 \pm 2.3$ years and BMI was $21.8 \pm 3.5 \mathrm{~kg} / \mathrm{m}^{2}$. The average BMI of women (10 subjects) was $19.3 \mathrm{~kg} / \mathrm{m}^{2}$ and men (20 subjects) was $23.1 \mathrm{~kg} / \mathrm{m}^{2}$. The mean plasma glucose, IRI, total GIP, active GLP-1, and IRG levels in the subjects are summarized in Figure 1. The mean plasma glucose and IRI peaked at 30 minutes (Figure 1A).

The mean active GLP-1 peaked at 15 minutes and the peak level of active GLP-1 was $10.6 \mathrm{pmol} / \mathrm{L}$. The level of total GIP increased steeply in 15 minutes, and thereafter increased gradually with time, whereas the IRG gradually decreased during the observation period. The peak level of total GIP was $265.5 \mathrm{pg} / \mathrm{mL}$ (Figure 1B).

The total GIP-AUC $C_{0-120}$ was related to the IRI-AUC $_{0-120}(R=0.39, P<0.05)$, II $(R=0.40$, $P<0.05)$, and $\Delta$ IRI between 0 and 120 minutes $(R=0.40, P<0.05)$, as shown in Figure 2A, B, and $\mathrm{C}$, respectively. Conversely, the active GLP-1-AUC $_{0-120}$ was inversely correlated with $\Delta$ glucose between 0 and 30 minutes $(R=-0.47$, 
Table 1. Clinical characteristics of 30 Japanese subjects with normal glucose tolerance.

\begin{tabular}{lc}
\hline & Week 0 \\
\hline Age, years & $24.7 \pm 2.3$ \\
\hline Gender, $n$ & 20 \\
$\quad$ Men & 10 \\
$\quad$ Women & $1.67 \pm 0.08$ \\
\hline Height, $\mathrm{m}$ & $60.8 \pm 11.6$ \\
Body weight, kg & $21.8 \pm 3.5$ \\
BMI, kg/m ${ }^{2}$ & $76.2 \pm 11.6$ \\
Waist circumference, cm & $1.1 \pm 0.8$ \\
HOMA-R & $68.3 \pm 45.6$ \\
HOMA- $\beta, \%$ & $0.8 \pm 0.5$ \\
Insulinogenic index & {$[+] 13 /[-] 17$} \\
Family history of diabetes* & \\
(presence [+]/absence [-]), $n$ & \\
\hline
\end{tabular}

Of the 13 subjects with the presence of a

family history:

Subjects with first-degree relative, $n \quad 4$

Subjects with second-degree relative, $n \quad 8$

Subjects with third-degree relative, $n \quad 1$

*Defined as subjects with a first- to third-degree relative with T2DM.

$\mathrm{BMI}=$ body mass index HOMA-R=homeostasis model assessment for insulin resistance; HOMA- $\beta=$ homeostasis model assessment for insulin secretion; T2DM=type 2 diabetes mellitus.

$P<0.01)$ and $\Delta$ IRG between 0 and 30 minutes $(R=-0.40, P<0.05)$, as shown in Figure $3 \mathrm{~A}$ and $\mathrm{B}$, respectively.

Body weight was correlated with HOMA-R $(R=0.50, P<0.01)$, II $(R=0.40, P<0.05)$, and HOMA- $\beta(R=0.37, P<0.05)$. BMI was correlated with HOMA-R $(R=0.50, P<0.01)$ and HOMA- $\beta$ $(R=0.37, P<0.05)$, and waist circumference was correlated with HOMA-R $(R=0.44, P<0.05)$ and HOMA- $\beta(R=0.39, P<0.05)$. However, body weight, BMI, waist circumference, height, and gender were not related to the secretory response of total GIP ( $\Delta$ GIP between 0 minutes and 15 , $30,60,120$ minutes, and GIP-AUC $\left.{ }_{0-120}\right)$, active GLP-1 ( $\Delta$ active GLP-1 between 0 minutes and 15,
Figure 1. Results of oral glucose tolerance test in (A) plasma glucose and insulin (B) glucagon, total glucosedependent insulinotropic peptide, and active glucagon-like peptide-1. Data are calculated as mean $\pm S D$. GIP=glucosedependent insulinotropic peptide; GLP-1=glucagonlike peptide-1; IRG=immunoreactive glucagon; IRI=immunoreactive insulin.
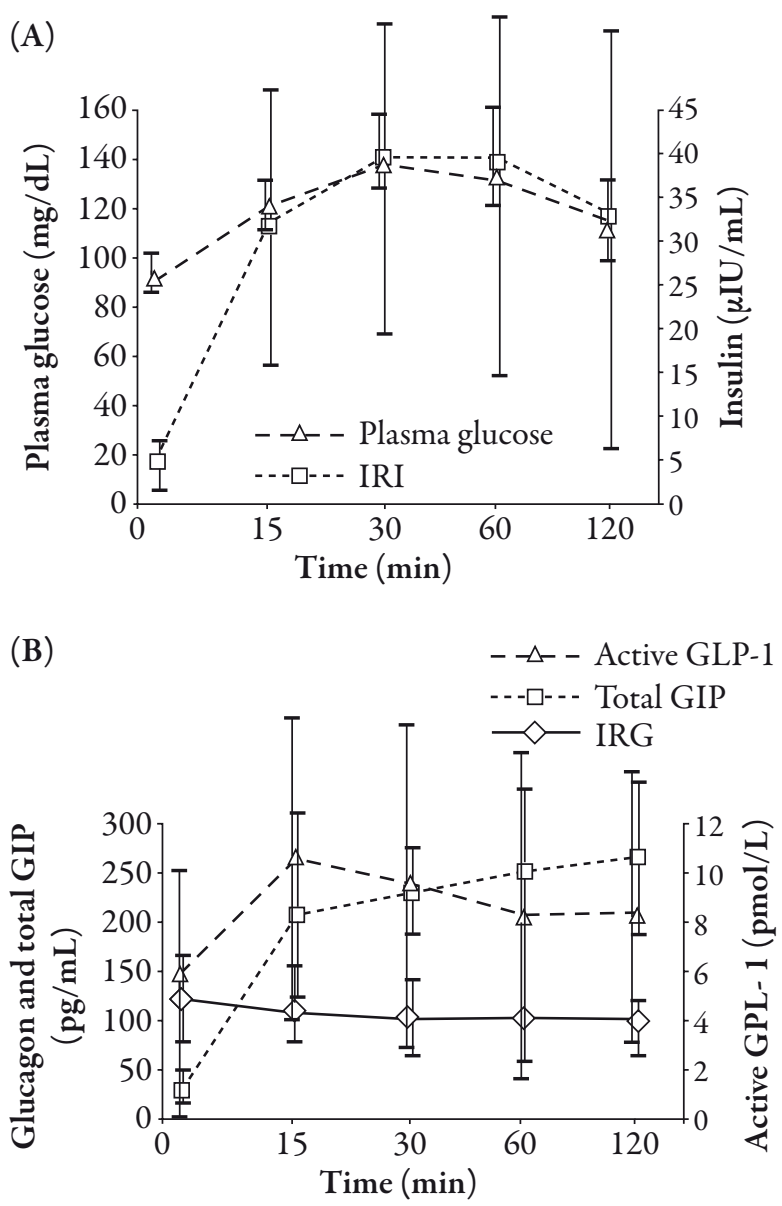

30, 60, 120 minutes, and active GLP-1-AUC ${ }_{0-120}$ ), and IRG ( $\triangle$ IRG between 0 minutes and 15,30 , 60, 120 minutes, and IRG-AUC $\mathrm{A}-120_{0}$ ).

The presence or absence of T2DM family history was not correlated with BMI, waist circumference, HOMA-R, II, HOMA- $\beta$, and IRI-AUC $_{0-120}$ as shown in Table 2. It was not correlated with the secretory response of active GLP-1 ( $\Delta$ active GLP-1 between 0 minutes and $15,30,60,120$ minutes, and active GLP-1$\mathrm{AUC}_{0-120}$ ) and IRG ( $\triangle$ IRG between 0 minutes and $15,30,60,120$ minutes, and IRG- 
Figure 2. (A) Correlation between total glucose-dependent insulinotropic polypeptide (GIP) area under the curve $(\mathrm{AUC})_{0-120}$ and immunoreactive insulin (IRI)-AUC ${ }_{0-120}$ $(y=1.797 x+205.79 ; R=0.39 ; P<0.05)$. (B) Correlation between total GIP-AUC ${ }_{0-120}$ and insulinogenic index $(y=7086.1 x+21,774 ; R=0.40 ; P<0.05)$. (C) Correlation between total GIP-AUC ${ }_{0-120}$ and $\Delta$ IRI between 0 and 120 minutes $(y=140.35 x+24,012 ; R=0.40 ; P<0.05)$. $\mathrm{AUC}=$ area under the curve; GIP=glucose-dependent insulinotropic peptide; $\mathrm{II}=$ insulinogenic index;

IRI=immunoreactive insulin.
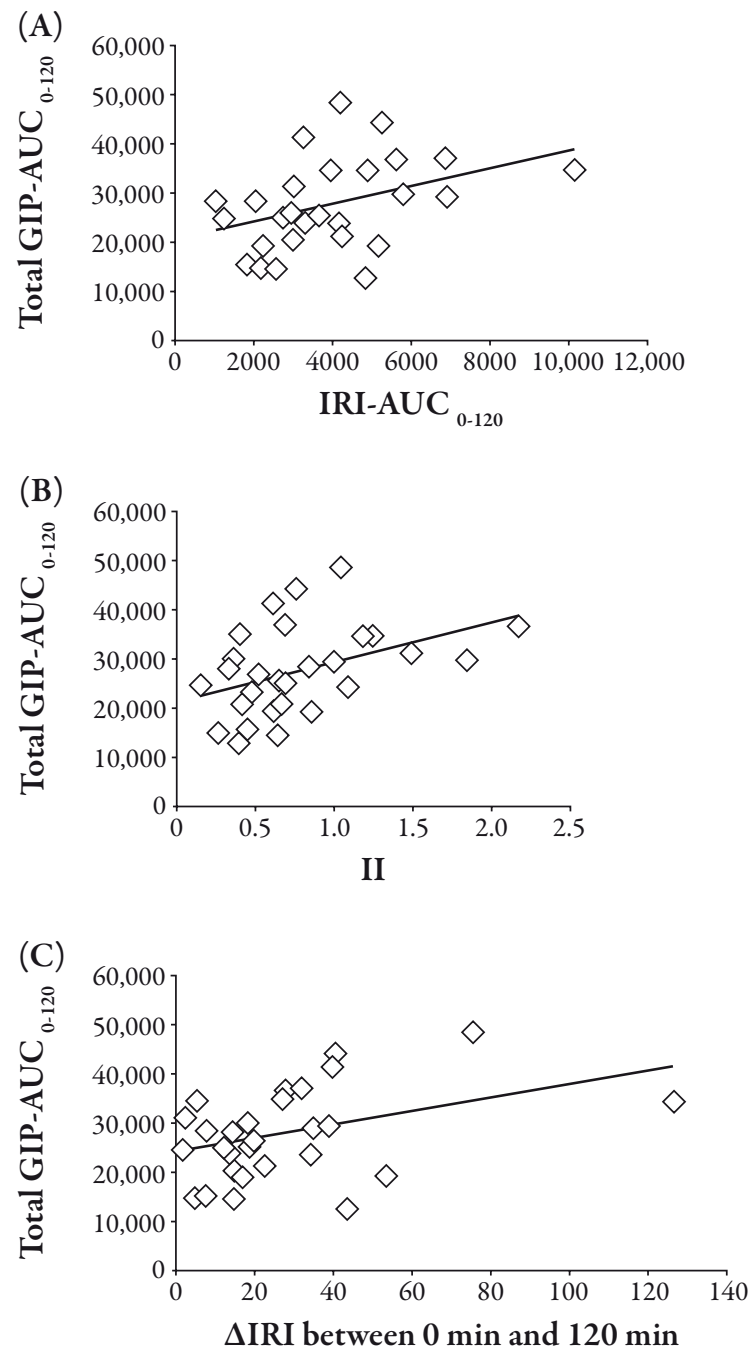

$\left.\mathrm{AUC}_{0-120}\right)$, respectively. However, $\Delta$ total GIP between 0 and 15 minutes $(R=0.54, P<0.01)$, $\Delta$ total GIP between 0 and 30 minutes $(R=0.39, P<0.05)$, and the total GIP-AUC ${ }_{0-120}$ $(R=0.39, P<0.05)$ in subjects with a family history of diabetes were significantly higher
Figure 3. (A) Correlation between active glucagon-like peptide-1 (GLP-1) area under the curve (AUC) $)_{0-120}$ and $\Delta$ glucose between 0 and 30 minutes $(y=-19.551 x$ +1920.9; $R=-0.47 ; P<0.01)$. (B) Correlation between active GLP-1-AUC ${ }_{0-120}$ and $\Delta$ immunoreactive glucagon (IRG) between 0 and 30 minutes $(y=-16.545 x+720.37$; $R=-0.40 ; P<0.05)$. AUC=area under the curve; $\mathrm{GIP}=$ glucose-dependent insulinotropic peptide; $\mathrm{IRG}=\mathrm{immunoreactive} \mathrm{glucagon}$.

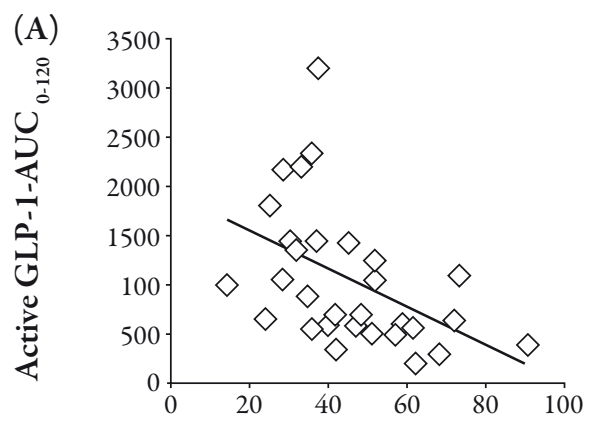

$\Delta$ glucose between $0 \mathrm{~min}$ and $30 \mathrm{~min}$

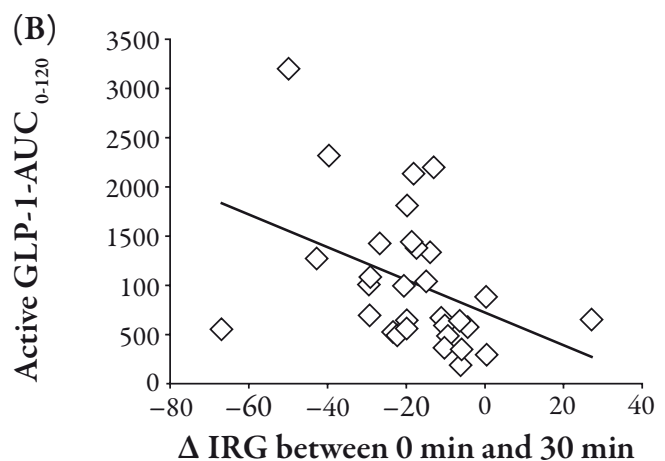

than those subjects without a family history of diabetes. In order to confirm this, unpaired $t$-tests were used to examine whether there was a difference between the $\Delta$ total GIP between 0 and 15 minutes, $\Delta$ total GIP between 0 and 30 minutes, and GIP-AUC ${ }_{0-120}$ in subjects with a family history of diabetes or no family history of diabetes. Total GIP$\mathrm{AUC}_{0-120}(P=0.039)$ in subjects with a family history of diabetes were significantly higher than those subjects without a family history of diabetes, and as shown in Figure $4, \Delta$ total GIP between 0 and 15 minutes $(P=0.0032)$ and $\Delta$ total GIP between 0 and 30 minutes $(P=0.041)$ in subjects with a family history of 
Table 2. Clinical characteristics of the enrolled subjects with or without a family history of diabetes.

\begin{tabular}{lccc}
\hline & \multicolumn{2}{c}{ Family history of diabetes $^{*}$} & \\
\cline { 2 - 3 } & Presence $(+)$ & Absence $(-)$ & P value \\
\hline Number of subjects & 13 & 17 & \\
Age, years & $24.8 \pm 2.7$ & $24.5 \pm 1.9$ & NS \\
BMI, $\mathrm{kg} / \mathrm{m}^{2}$ & $21.2 \pm 3.4$ & $22.3 \pm 3.6$ & $\mathrm{NS}$ \\
Waist circumference, cm & $73.8 \pm 12.6$ & $78.1 \pm 10.8$ & $\mathrm{NS}$ \\
HOMA-R & $1.1 \pm 0.9$ & $1.2 \pm 0.6$ & $\mathrm{NS}$ \\
HOMA- $\beta$, $\%$ & $64.3 \pm 49.8$ & $71.4 \pm 43.4$ & $\mathrm{NS}$ \\
Insulinogenic index & $0.8 \pm 0.5$ & $0.8 \pm 0.5$ & $\mathrm{NS}$ \\
IRI-AUC $_{0-120}, \mu \mathrm{U} \mathrm{h} / \mathrm{mL}$ & $3840.2 \pm 1493.0$ & $4398.4 \pm 2321.5$ & $\mathrm{NS}$ \\
\hline
\end{tabular}

${ }^{*}$ Defined as subjects with first- to third-degree relatives with T2DM.

$\mathrm{AUC}=$ area under the curve; $\mathrm{BMI}=$ body mass index; HOMA-R=homeostasis model assessment for insulin resistance; HOMA- $\beta=$ homeostasis model assessment for insulin secretion; IRI=immunoreactive insulin; NS=nonsignificant; T2DM=type 2 diabetes mellitus.

Figure 4. Correlation of $\Delta$ glucose-dependent insulinotropic polypeptide (GIP) and a family history of type 2 diabetes mellitus (T2DM), defined as having a first- to third-degree relative with T2DM. ${ }^{* *} P<0.01$. ${ }^{*} P<0.05$. DM=diabetes mellitus; GIP = glucose-dependent insulinotropic peptide; $\mathrm{NS}=$ nonsignificant.

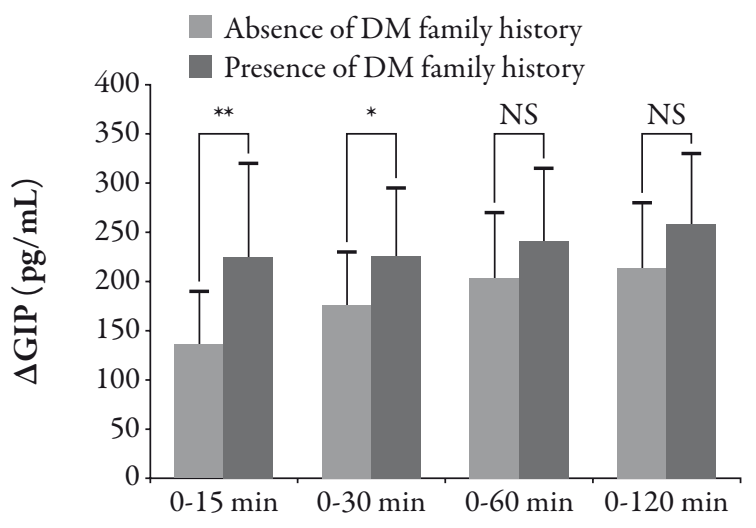

diabetes were significantly higher than those subjects without a family history of diabetes.

\section{DISCUSSION}

The analytical data of incretin responses and kinetics of healthy Japanese subjects are scant; ${ }^{5-7}$ therefore, in the present study 30 Japanese NGT subjects were recruited.
Nauck et al. ${ }^{10}$ administered synthetic human GIP, GLP-1, and placebo under hyperglycemic clamp conditions in nine T2DM and nine ageand weight-matched NGT subjects. Both GIP and GLP-1 (7-36 amide) dose-dependently augmented insulin secretion in both the T2DM and NGT group. ${ }^{10}$ Cataland et al. ${ }^{11}$ gave 75 g glucose to 21 healthy volunteers, and their serum GIP levels increased after oral glucose ingestion.

The present study shows that the total GIP$\mathrm{AUC}_{0-120}$ in healthy Japanese subjects positively correlated with the IRI-AUC ${ }_{0-120}(P<0.05)$, II $(P<0.05)$, and $\Delta$ IRI between 0 and 120 minutes $(P<0.05)$. The present study has demonstrated that GIP clearly augmented insulin secretion in response to an oral glucose load in healthy subjects, which suggests that the secretory response of total GIP, which is secreted from $\mathrm{K}$ cells primarily in the proximal intestine after glucose ingestion, could be a potent trigger and/or stimulant of insulin secretion in healthy subjects.

Conversely, active GLP-1-AUC ${ }_{0-120}$ was not related to IRI-AUC ${ }_{0-120}$ and II. Active GLP-1 did not show any significant augmentation of insulin secretion in Japanese NGT subjects. 
However, active GLP-1-AUC $\mathrm{C}_{0-120}$ was correlated inversely both with $\Delta$ glucose between 0 and 30 minutes $(P<0.01)$ and with $\Delta$ IRG between 0 and 30 minutes $(P<0.05)$. This means that GLP-1 may exert its glucoregulatory action via the suppression of glucagon secretion rather than the stimulation of insulin secretion in healthy Japanese subjects. This effect of GLP-1 possibly contributes to lower the plasma glucose level as a result of reduction in hepatic glucose output. ${ }^{1}$ The secretory response of GLP- 1 has been reported to be decreased in $\mathrm{T} 2 \mathrm{DM},{ }^{3,4,12}$ which could weaken the incretin effect of GLP-1 on the reduction in hepatic glucose output.

In addition, GLP-1 may also lower plasma glucose levels by retarding gastric emptying, because there is an inverse relationship between gastric emptying of glucose and plasma GLP-1. ${ }^{13}$ To establish the precise mechanism of the inverse relationship between GLP-1 secretion and plasma glucose, the function of gastric emptying of glucose needs to be examined.

The key factors regulating the GIP/GLP-1 response after glucose ingestion by NGT and abnormal glucose tolerant subjects are not well understood. Vollmer et al. ${ }^{14}$ reported that female gender was positively related to GLP-1 concentration. Carroll conducted a study to determine the influence of BMI and gender on postprandial hormone responses such as insulin, leptin, ghrelin, active GLP-1, and glucagon. He found that men had significantly greater fasting $(P=0.02)$ and postprandial $(P=0.03)$ glucagon, and men tended to have higher GLP-1 concentrations $(P=0.06)$. Obese subjects had higher fasting glucose and insulin concentrations, while BMI did not affect the postprandial GLP-1 response. ${ }^{15}$ Several studies have demonstrated that gender did not influence glucagon responses to stimuli such as exercise and hypoglycemia. ${ }^{16-18}$ Therefore, in the present study, the influence of gender, height, body weight, BMI or waist circumference on the incretin hormones and glucagon in healthy Japanese subjects was examined. However, no significant relationship among these factors in Japanese NGT subjects was found. Neither gender nor physical constitution affected the secretion of incretin hormones in the Japanese subjects.

In addition, we examined whether a family history of diabetes (presence or absence of T2DM patients within the third degree of kinship) was correlated with the level and/or the response of incretin hormones, because Japanese patients with T2DM usually have impaired insulin secretion even in the early phase of diabetes rather than insulin resistance. ${ }^{19}$ In earlier studies in Western countries, the incretin effect in relatives of T2DM patients has been examined, and it is still controversial. In a German study, a lower insulin secretory response to exogenous GIP in first-degree relatives of patients with T2DM was shown, ${ }^{20}$ and in a Danish study, the daytime (after meals) AUC for plasma GIP was significantly increased in the relatives of diabetes patients compared with control subjects without any family history of diabetes. ${ }^{21}$ However, in another German study, the incretin effects were similar in first-degree relatives of patients with T2DM and healthy control subjects. ${ }^{22}$ As there had been no attempt to reveal the relationship between a family history of diabetes and incretin response in Japanese subjects, we enrolled Japanese subjects who were NGT with or without a family history of diabetes. Interestingly, we found that $\Delta$ total GIP between 0 and 15 minutes $(R=0.54, P<0.01)$, $\Delta$ total GIP between 0 and 30 minutes $(R=0.39$, $P<0.05)$, and the total GIP-AUC ${ }_{0-120}(R=0.39$, $P<0.05)$ in the subjects with a family history of diabetes were significantly higher than those in the subjects without a family history of diabetes. Conversely, IRI, HOMA-R, HOMA- $\beta$, II, active GLP-1, and IRG were not correlated 
with the presence or absence of a family history of diabetes.

It has been speculated that the loss of insulinotropic action of GIP in T2DM might occur as a result of either chronic desensitization of GIP receptors, ${ }^{23}$ or a reduction in the expression of GIP receptors on pancreatic $\beta$ cells. ${ }^{24,25}$ Both abnormalities of GIP receptors might have already been induced in an NGT state with the presence of a family history, and a hypersecretion of GIP could potentially compensate for a reduced insulinotropic effectiveness of GIP, which could enhance insulin secretion particularly in the early phase in response to a glucose load.

Another hypothesis to account for the hypersecretion of GIP in NGT subjects with T2DM family history is the rapid gastric emptying. Since Phillips et al. ${ }^{26}$ reported that recently diagnosed T2DM patients emptied their stomach more rapidly than nondiabetic control subjects, in the subjects with a family history of T2DM, the GIP secretion from the upper small intestine may already be augmented by rapid gastric emptying even in an NGT state. Furthermore, whether the background mechanism of the phenomenon would depend on the differences in the rate of glucose absorption in the small intestine and density of $\mathrm{K}$ cells should be examined in the future.

The augmented response of GIP after glucose load in subjects with a family history of T2DM in the present study could be related, in part, to the onset mechanism of Japanese T2DM patients, although further study is required. The low number of subjects is acknowledged as a limitation of the study.

In conclusion, the present study was designed to investigate the secretory patterns of two incretin hormones to OGTT and the relationship between incretin hormones and glucose, insulin, or glucagon response in healthy Japanese subjects. The results demonstrate that, at least in subjects enrolled in the study, GIP from the upper small intestine may play a role as an insulinotropic hormone and GLP-1 may play a role as a glucagonostatic hormone collaboratively. Furthermore, healthy subjects with a family history of diabetes who have normal glucose tolerance exert a significantly higher GIP response, especially in the early phase of GIP secretion in response to an oral glucose load compared with those without a family history of T2DM.

\section{ACKNOWLEDGMENTS}

The authors declare that there is no duality of interest associated with this manuscript.

Dr. Namba is the guarantor for this article, and takes responsibility for the integrity of the article as a whole.

Open Access. This article is distributed under the terms of the Creative Commons Attribution Noncommercial License which permits any noncommercial use, distribution, and reproduction in any medium, provided the original author(s) and source are credited.

\section{REFERENCES}

1. Kim W, Egan JM. The role of incretins in glucose homeostasis and diabetes treatment. Pharmacol Rev. 2008;60:470-512.

2. Kelly KR, Brooks LM, Solomon TP, Kashyap SR, O'Leary VB, Kirwan JP. The glucose-dependent insulinotropic polypeptide and glucose-stimulated insulin response to exercise training and diet in obesity. Am J Physiol Endocrinol Metab. 2009;296:E1269-E1274.

3. Vilsboll T, Krarup T, Deacon CF, Madsbad S, Holst JJ. Reduced postprandial concentrations of intact biologically active glucagon-like peptide 1 in type 2 diabetic patients. Diabetes. 2001;50: 609-613.

4. Knop FK, Vilsboll T, Hojberg PV, et al. Reduced incretin effect in type 2 diabetes: cause or 
consequence of the diabetic state? Diabetes. 2007;56:1951-1959.

5. Lee S, Yabe D, Nohtomi K, et al. Intact glucagonlike peptide-1 levels are not decreased in Japanese patients with type 2 diabetes. Endocr J. 2009;57:119-126

6. Kozawa J, Okita K, Imagawa A, Holst JJ, Yamagata K, Shimomura I. Similar incretin secretion in obese and nonobese Japanese subjects with type 2 diabetes. Biochem Biophys Res Commun. 2010;393:410-413

7. Yabe D, Kuroe A, Lee S, et al. Little enhancement of meal-induced glucagon-like peptide 1 secretion in Japanese: comparison of type 2 diabetes patients and healthy controls. J. Diabetes Invest. 2010;1: 56-59

8. Matthews, DR, Hosker JP, Rudenski AS, Naylor BA, Treacher DF, Turner RC. Homeostasis model assessment: insulin resistance and beta-cell function from fasting plasma glucose and insulin concentrations in man. Diabetologia. 1985;28: 412-419.

9. Wareham NJ, Phillips DI, Byrne CD, Hales CN. The 30 minute insulin incremental response in an oral glucose tolerance test as a measure of insulin secretion. Diabet Med. 1995;12:931.

10. Nauck MA, Heimesaat MM, Orskov C, Holst JJ, Ebert R, Creutzfelt W. Preserved incretin activity of glucagon-like peptide 1 [7-36 amide] but not of synthetic human gastric inhibitory polypeptide in patients with type-2 diabetes mellitus. J Clin Invest. 1993;91:301-307.

11. Cataland S, Crockett SE, Brown JC, Mazzaferri ER. Gastric inhibitory polypeptide (GIP) stimulation by oral glucose in man. J Clin Endocrinol Metab. 1974;39:223-228.

12. Toft-Nielsen MB, Damholt MB, Madsbad S, et al. Determinants of the impaired secretion of glucagon-like peptide- 1 in type 2 diabetic patients. J Clin Endocrinol Metab. 2001;86:3717-3723.

13. Wishart JM, Horowitz M, Morris HA, Jones KL, Nauck MA. Relation between gastric emptying of glucose and plasma concentrations of glucagonlike peptide-1. Peptide. 1998;19:1049-1053.

14. Vollmer K, Holst JJ, Baller B, et al. Predictors of incretin concentrations in subjects with normal, impaired, and diabetic glucose tolerance. Diabetes. 2008;57:678-687.
15. Carroll JF, Kaiser KA, Franks SF, Deere C, Caffrey JL. Influence of BMI and gender on postprandial hormone responses. Obesity. 2007;15:2974-2983.

16. Amiel SA, Maran A, Powrie JK, Umpleby AM, Macdonald IA. Gender differences in counterregulation to hypoglycaemia. Diabetologia. 1993;36:460-464.

17. Galassetti P, Tate D, Neill RA, Morrey S, Davis SN. Effect of gender on counterregulatory responses to euglycemic exercise in type 1 diabetes. J Clin Endocrinol Metab. 2002;87:5144-5150.

18. Diamond MP, Jones T, Caprio S, et al. Gender influences counterregulatory hormone responses to hypoglycemia. Metabolism. 1993;42:1568-1572.

19. Fukushima M, Suzuki H, Seino Y. Insulin secretion capacity in the development from normal glucose tolerance to type 2 diabetes. Diabetes Res Clin Pract. 2004;66S:s37-s43

20. Meier JJ, Hucking K, Holst JJ, Deacon CF, Schmiegel WH, Nauck MA. Reduced insulinotropic effect of gastric inhibitory polypeptide in first-degree relatives of patients with type 2 diabetes. Diabetes. 2001;50:2497-2504.

21. Nyholm B, Walker M, Gravholt CH, et al. Twentyfour-hour insulin secretion rates, circulating concentrations of fuel substrates and gut incretin hormones in healthy offspring of type II (noninsulin-dependent) diabetic parents: evidence of several aberrations. Diabetologia. 1999;42:13141323.

22. Nauck, MA, El-Ouaghlidi A, Gabrys B, et al. Secretion of incretin hormones (GIP and GLP-1) and incretin effect after oral glucose in first-degree relatives of patients with type 2 diabetes. Regul Pept. 2004;122:209-217.

23. Tseng CC, Boylan MO, Jarboe LA, Usdin TB, Wolfe MM. Chronic desensitization of the glucosedependent insulinotropic polypeptide receptor in diabetic rats. Am J Physiol. 1996;270:E661-E666.

24. Holst JJ, Gromada J, Nauck MA. The pathogenesis of NIDDM involves a defective expression of the GIP receptor. Diabetologia. 1997;40:984-986.

25. Zhou J, Livak MF, Bernier M, et al. Ubiquitination is involved in glucose-mediated downregulation of GIP receptors in islets. Am J Physiol Endocrinol Metab. 2007;293:E538-E547.

26. Phillips WT, Schwartz JG, McMahan CA. Rapid gastric emptying of an oral glucose solution in type 2 diabetic patients. J Nucl Med. 1992;8: 1496-1500. 